\title{
EFFECTS OF TELMISARTAN ON PLASMA INTERLEUKIN-6 AND C-REACTIVE PROTEIN LEVELS IN MONOSODIUM GLUTAMATE-INDUCED OBESITY IN WISTAR ALBINO RATS
}

\author{
VENKATESH KMํㅜㄹ ${ }^{\text {, SRIRAM BS }}{ }^{1}$, RAVICHANDRA V ${ }^{2 *}$, RAJENDRA HOLLA ${ }^{3}$
}

Department of Pharmacology, K. S. Hegde Medical Academy, Deralakatte, Karnataka, India. Email: ravi75chandra@yahoo.in

Received: 27 February 2020, Revised and Accepted: 15 April 2020

ABSTRACT

Objectives: The objectives of this study were to evaluate the effects of telmisartan on plasma interleukin (IL)-6 and C-reactive protein (CRP) levels in monosodium glutamate (MSG)-induced obesity in Wistar albino rats.

Methods: MSG at the dose of $500 \mathrm{mg} / \mathrm{kg}$ body weight is dissolved in distilled water and administered for 22 days. On the $9^{\text {th }}$ day, telmisartan $7.5 \mathrm{mg} / \mathrm{kg}$ body weight is administered. After completion of experiment, body weight and biochemical parameters such as plasma IL- 6 and CRP levels are measured using enzyme-linked immunosorbent assay.

Results: Telmisartan significantly decreased plasma IL-6 and CRP levels in MSG-treated obese rats.

Conclusion: Telmisartan, probably through its peroxisome proliferator-activated receptor- $\gamma$ agonistic activity, produces significant anti-obesity effects in rats and may help in treating obese patients with metabolic syndrome.

Keywords: Monosodium glutamate, Telmisartan, Interlukin-6, C-reactive protein.

(C) 2020 The Authors. Published by Innovare Academic Sciences Pvt Ltd. This is an open access article under the CC BY license (http://creativecommons. org/licenses/by/4. 0/) DOI: http://dx.doi.org/10.22159/ajpcr.2020.v13i6.37286

\section{INTRODUCTION}

Obesity is a chronic and progressive disease that is rapidly increasing in prevalence. It is a condition characterized by abnormal or excessive fat deposition that poses a risk to health. In general, the crude population measure to obesity is body mass index (BMI); it is persons weight (in kg) divided by square of his/her height (in m). A person with a BMI of 30 or more is generally considered obese. Annually, obesity is responsible for 2.8 million deaths and 35.8 million disability-adjusted life-years in population worldwide [1].

Obesity is associated with cardiovascular morbidity, hypertension, dyslipidemia osteoarthritis, type 2 diabetes mellitus, and depression and increases the prevalence of cancer [2,3]. Modern anti-obesity drugs produce severe side effects so the need for reliable and effective drugs is in demand. For safer and effective alternative, weight management requires a better understanding of the biology of appetite and metabolism [4]. Monosodium glutamate (MSG), also known as Ajinomoto, widely used as a taste enhancer which is a sodium salt of glutamic acid [5]. MSG is found in dairy products, fish, mushroom, and tomatoes and used in variety of food products such as processed food and snacks [6]. MSG at the dose of $500 \mathrm{mg} / \mathrm{kg}$ body weight is found to produce obesity in rats which serve as an experimental obesity model [7]. Significant elevation in plasma interleukin (IL)-6 and C-reactive protein (CRP) levels in obese subjects in proportion to the degree of adiposity suggests that they may play a major role in the pathogenesis of obesity $[8,9]$.

\section{METHODS}

MSG was procured from Sisco Laboratories Pvt. Ltd., India. IL-6 and CRP enzyme-linked immunosorbent assay (ELISA) kits were purchased from Krishgen Pvt., Ltd., India and standard telmisartan $40 \mathrm{mg}$ tablets (Telma 40) from Glenmark Pharmaceuticals Ltd., India.

Female rats of 3 months old (250-300 g) were used for the study, after obtaining permission from the Institutional Animal Ethics Committee (115/1999) K. S. Hegde Medical Academy, Mangalore.
They were kept in a standard laboratory environment with laboratory food and water ad libitum.

$\mathrm{p}<0.05$ was considered as statistically significant

The animals were grouped and administered drugs as follows ( $\mathrm{n}=6$ each):

- Group 1 (Control - C): Distilled water (1.5 ml, P.0)

- Group 2 (Positive control - PC): MSG (500 mg/kg) orally for 21 days

- Group 3 (Control + Telmisartan -C+T): Telmisartan (5 mg/kg) started on the $9^{\text {th }}$ day and continued until $21^{\text {st }}$ day

- Group 4 (Positive control + Telmisartan - PC+T): Telmisartan $(5 \mathrm{mg} / \mathrm{kg})$ started on the $9^{\text {th }}$ day and continued till the $21^{\text {st }}$ day.

The MSG and telmisartan were administered orally after dissolving in distilled water. The recommended dose of telmisartan in a human was used to calculate the dose for experimental animal. The selection dose of telmisartan used was based on a previous study.

On the $23^{\text {rd }}$ day, blood was drawn from the tail vein and plasma was subjected for analysis.

\section{IL-6 levels estimation}

IL-6 was quantified by ELISA according to the manufacturer's instructions (Krishgen, India). The IL- 6 concentration in given blood samples with different treatment groups was estimated using the calibration curve provided with the kit [10].

\section{C-RP estimation}

C-RP was quantified by ELISA according to the manufacturer's instructions (Krishgen, India). The C-RP concentration in given blood samples with different treatment groups was estimated using the calibration curve provided with the kit [11].

\section{Statistical analysis}

Statistical analysis was performed using GraphPad Prism version 5.0. One-way analysis of variance was performed followed by 
Tukey's test as post hoc. $\mathrm{p}<0.05$ was considered as statistically significant.

\section{RESULTS}

Plasma IL-6 levels

The plasma IL-6 levels were significantly increased in positive control (MSG) group when compared to control (Fig. 1). The intervention groups treated with telmisartan showed a significant decrease in plasma IL-6 levels and there were no significant changes in telmisartan alone treated groups.

\section{Plasma CRP levels}

The plasma CRP levels were significantly increased in the positive control group (MSG) indicating inflammation (Fig. 2). The intervention groups treated with telmisartan, both showed a significant decrease in plasma CRP levels, and there are no significant changes in telmisartan alone treated groups.

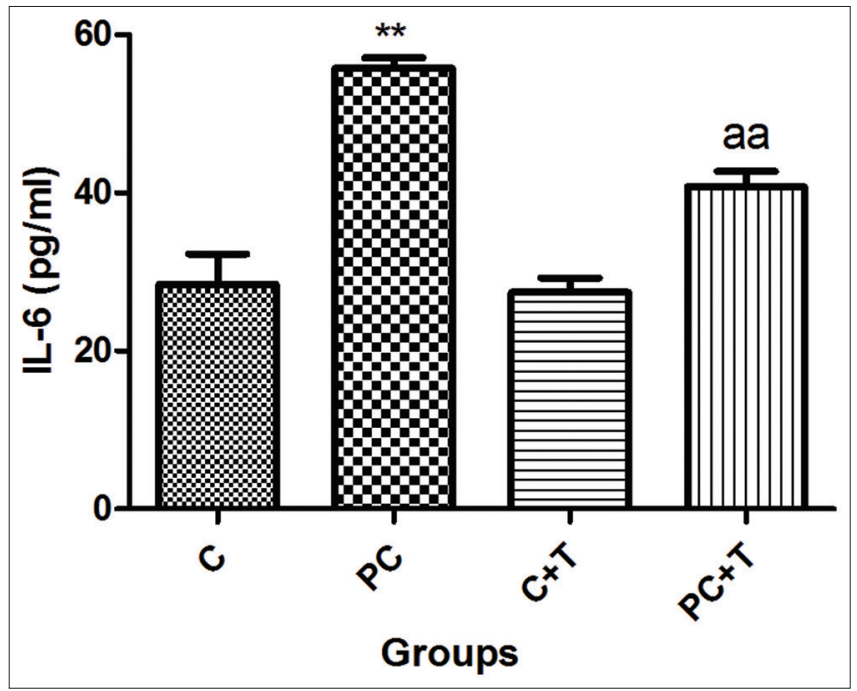

Fig. 1: Effect of various treatments on plasma interleukin-6 levels $\left({ }^{* *} \mathbf{p}<0.01\right.$ compared to control; aa $\mathbf{p}<0.01$ compared to positive control); $n=6$ in each group; data are represented as mean \pm standard deviation

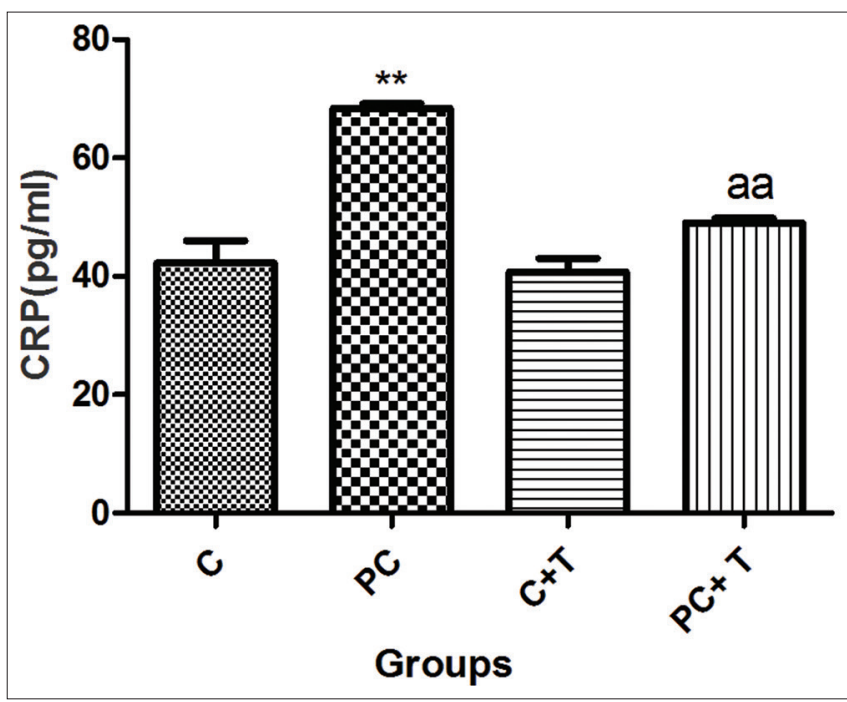

Fig. 2: Effect of various treatments on plasma C-reactive protein levels ( $* * \mathbf{p}<0.01$ compared to control; aa $\mathrm{p}<0.01$ compared to positive control); $n=6$ in each group; data are represented as mean \pm standard deviation

\section{DISCUSSION}

Obesity is widely associated with other disorders such as diabetes mellitus, hypertension, hyperlipidemia, and also cancer [12]. Obese people are more prone to develop insulin resistance when compared to normal [13]. It has also been observed in studies that obesity leads to premature aging due to telomere attrition [14]. Therefore, prevention and treatment of obesity plays a key role in the management of its associated disorders and its complications.

In the present study, anti-obesity effects of telmisartan on MSG-induced obesity were evaluated using the estimation of plasma IL- 6 and CRP levels by ELISA of female Wistar albino rats. The majority of drugs used in anti-obesity treatment in pipeline are known to cause severe adverse effects, thus decreasing the compliance of the treatment [15]. Since inflammation is associated with obesity estimation of plasma, IL-6 and CRP levels play a key role in understanding the effect of drugs in the management of obesity [16].

Recent studies indicate the role of IL- 6 and CRP as an inflammatory marker in obesity; therefore, drugs which decrease IL- 6 and CRP levels help in the management of obesity [17]. In the study, telmisartan antagonized the inflammation-mediated obesity induced by feeding mice with high-fat diet [18]. Telmisartan acts as an agonist of peroxisome proliferator-activated receptor- $\delta$ pathway which provides protection against inflammation associated with obesity which could be the possible mechanism behind its anti-obesity effects [19]. Recent evidence suggests that the structure of telmisartan pleiotropic effects is superior to other sartans which modulate the binding of fat to the adipose tissue. Its pharmacokinetic profile also suggests that due to high lipophilicity, it enters the adipocyte and prevents the accumulation of lipids droplets, thus preventing the activation of inflammatory cytokines [20].

Interestingly, several other studies support the role of CRP and IL-6 levels changes in obesity, and the current study helps in providing additional evidence in employing telmisartan as a potential drug in prevention and management of obesity [21-23].

\section{CONCLUSION}

Telmisartan has shown a significant decrease in reducing plasma IL-6 and CRP levels in MSG-treated obese groups, thereby decreasing inflammation associated with obesity. However, further studies, including the evaluation of its effect on the biochemical, molecular, and cellular pathways, are required to establish its role as an anti-obesity drug.

\section{AUTHORS' CONTRIBUTIONS}

Dr. Venkatesh KM - Conducted the study, Mr. Sriram BS - Estimations of parameters, Dr. Ravichandra V - Manuscript preparation, and Dr. Rajendra Holla - Manuscript preparation.

\section{FUNDING}

Self-funded.

\section{CONFLICTS OF INTEREST}

None.

\section{REFERENCES}

1. World Health Organization. Obesity Data and Statistics. Geneva: World Health Organization; 2017. Available from: http://www.euro.who.int/en/health-topics/noncommunicable-diseases/o besity/data-and-statistics6.

2. Chowdhury MA, Uddin MJ, Khan HM, Haque MR. Type 2 diabetes and its correlates among adults in Bangladesh: A population based study. BMC Public Health 2015;15:1070

3. Kulie T, Slattengren A, Redmer J, Counts H, Eglash A, Schrager S. Obesity and women's health: An evidence-based review. J Am Board 
Fam Med 2011;24:75-85.

4. Colon-Gonzalez F, Kim GW, Lin JE, Valentino MA, Waldman SA. Obesity pharmacotherapy: What is next? Mol Aspect Med 2013;34:71-83.

5. Husarova V, Ostatnikov D. Monosodium glutamate toxic effects and their implications for human in-take: A review. JMED Res 2013;2013:608765.

6. Tawfik MS, Al-Badr N. Adverse effects of monosodium glutamate on liver and kidney functions in adult rats and potential protective effect of Vitamins C and E. Food Nutr Sci 2012;3:651-9.

7. Rhodes J, Titherley AC, Norman JA, Wood R, Lord DW. A survey of the monosodium glutamate content of foods and an estimation of the dietary intake of monosodium glutamate. Food Addit Contam 1991;8:663-72.

8. Sindhu S, Thomas R, Shihab P, Sriraman D, Behbehani K, Ahmed R. Obesity is a positive modulator of IL-6R and IL-6 expression in the subcutaneous adipose tissue: Significance for metabolic inflammation. PLoS One 2015;10:e133494.

9. Visser M, Bouter LM, McQuillan GM, Wener MH, Harris TB. Elevated $\mathrm{C}$-reactive protein levels in overweight and obese adults. JAMA 1999;282:2131-5.

10. Yoga R, Theis J, Walton M, Sutherland W. Interleukin-6 as an early marker for fat embolism. J Orthop Surg Res 2009;4:18.

11. Tunc-Ata M, Turgut G, Dalyanoglu MM, Turgut S. Examination of levels pentraxin-3, interleukin-6, and C-reactive protein in rat model acute and chronic exercise. J Exerc Rehabil 2017;13:279-83.

12. Segula D. Complications of obesity in adults: A short review of the literature. Malawi Med J 2014;26:20-4.

13. Kahn BB, Flier JS. Obesity and insulin resistance. J Clin Invest 2000;106:473-81.

14. Sriram BS, Ravichandra V. An experimental study evaluating the influence of quercetin on monosodium glutamate-induced depression in swiss albino male mice". Asian J Pharm Clin Res 2019;12:292-4.

15. Cheung BM, Cheung TT, Samaranayake NR. Safety of antiobesity drugs. Ther Adv Drug Saf 2013:4:171-81.

16. Jain V, Kumar A, Agarwala A, Vikram N, Ramakrishnan L. Adiponectin, interleukin-6 and high-sensitivity C-reactive protein levels inoverweight/ obese Indian children. Indian Pediatr 2017;54:848-50.

17. Mori Y, Itoh Y, Tajima N. Angiotensin II receptor blockers downsize adipocytes in spontaneously Type 2 diabetic rats with visceral fat obesity. Am J Hypertens 2007;20:431-6.

18. Feng X, Luo Z, Ma L, Ma S, Yang D, Zhao Z, et al. Angiotensin II receptor blocker telmisartan enhances running endurance of skeletal muscle through activation of the PPAR- $\delta$ /AMPK pathway. J Cell Mol Med 2011;15:1572-81.

19. He H, Yang D, Ma L, Luo Z, Ma S, Feng X, et al. Telmisartan prevents weight gain and obesity through activation of peroxisome proliferatoractivated receptor- $\delta$-Dependent pathways. Hypertension 2010;55:869-79.

20. Shimabukuro M, Tanaka H, Shimabukuro T. Effects of telmisartan on fat distribution in individuals with the metabolic syndrome. J Hypertens 2007;25:841-8.

21. Buggana SJ, Paturi MC, Prasad VV. 2,4-Substituted quinazoline as JAK2 Inhibitor: Docking And Molecular Dynamics Study. Int J Pharm Pharm Sci 2019;12:48-54.

22. Chandrasekaran R, Sivaraman T, Sivaramakrishnan S, Kumar JJ. A computational approach on understanding structural interactions of envelope protein of dengue virus bound with squalene, a prototype antiviral compound. Int J Pharm Pharm Sci 2019;11:113-6.

23. Fathy HM. Inhibition of tumour necrosis factor (TNF) activity by a new ergostane steroid from cleome droserifolia. Int J Pharm Pharm Sci 2018;10:139-42. 